

\title{
Editorials
}

\section{Images of Schools: 2020 Possible, Probable or Preferable?}

\author{
Lee Smalley ${ }^{1}$
}

There is no need to belabor the point that all aspects of our school system need to reexamine their role and operation. Hardly a week goes by where there is not further proof that we have a school system inconsistent with our aspirations for ourselves or our country. This school system includes teacher education, teachers, students, administrators, school boards, parents, research institutions, governmental bodies and any other group or institution that impacts on the operation of our schools.

What are we going to do about the school as a helping place?

What changes would come about if students, teachers, parents and administrators perceived schools as a helping place, not a sorting place? Studies continue to show that marking a misspelled word wrong and returning the paper days later, with no follow up or corrective action except for a lower grade, makes a mockery of instructional strategy. Thus, the emphasis is on punishment rather than instruction. "I told you once," replaces understanding and empathy.

The awarding of a grade of "F" should be discarded for anyone below the age of legal alcohol consumption or voting. We should consider young people incompletes, not failures, and adjust our policies and procedures accordingly. We need to keep performance constant and vary the time for students to achieve. We should perform as the doctor or lawyer and not give up on our clients until after they do, and even then, reluctantly and sadly.

What are we going to do about the school as a democratic place?

The vision of schools as a place to practice democratic skills and attitudes has either been dimmed or severely damaged by autocratic practices in the classroom and in the administrative offices. The traditional vertical hierarchy of line and staff, with the Board of Education on top and the teachers on the bottom (usually students are not shown), is based on the existence of an illiterate group who needs to be directed by the elite who are selected or born to rule. These conditions existed once in the army and the church, but they do not exist now in American schools.

The organizational chart should not reflect a ranking of salaries but should indicate responsibilities and competencies with horizontal networking necessary to encourage cooperation (like quality circles) rather than separation. This chart should graphically display the school system, emphasizing the importance of teachers, where they are not on the bottom. Students need to practice democratic skills and attitudes through decision making in classes as well as in schools. Let us mirror the representative republic we want our citizens to understand and participate in.

What are we going to do about the teacher as director?

Teachers generally teach as they were taught, as well as continuing those techniques that seem to be consistent with peer approval and support from administration and parents. Therefore, the teacher as teller continues far longer than is appropriate in this communication age. We have successfully rejected the radio, telephone and television as an instructional device and are doing the same thing with the computer. We are increasingly using computers to teach about themselves and not using them to teach history, geography, etc. Teachers still stand and talk while students sit and listen. Teachers work too hard during class time and students are too passive. Class time should be for students to test, reform and remodel information gained outside the classroom, increasingly through an expert system. These systems will be interactive, portable and accessible in shopping malls, homes, and schools.

1 Lee Smalley is Professor, Industrial \& Marketing Education Department, University of Wisconsin - Stout. 
Teachers should let the technical devices do the easy work- transferring information-and leave the more difficult task of developing generalizations and providing a social context to the information learned to the teacher-student.

What are we going to do about recognizing the importance of talent?

Most educators assign 100 percent of success or failure to environmental factors: college teachers blame high school, middle school, and elementary school teachers and parents. Nowhere does the role of inherited talent seem to play a part. If the only tool you have is a hammer, then all problems will look like nails! Yet in recent studies of identical twins raised apart conducted at the University of Minnesota researchers suggest that 60 percent of a person's personality characteristics such as learning style, risk taking, information-processing, extroversion or introversion and empathy are all extremely important in determining behavior. Yet, those traits are usually attributed only to learned behavior that can be changed or modified by teaching, whereas quite the contrary seems to be true.

Teachers should be helping students discover their talents and designing activities to encourage their strengths, rather than running an "animal" school where all the animals have to fly, climb, dig, run, jump and hide.

What are we going to do about teaching higher order thinking skills?

Bloom's taxonomy of the cognitive domain should have a large gap between the lowest three levels (knowledge, comprehension and application) and the highest three levels (analysis, synthesis and evaluation). The lowest three are product-oriented with one right answer - best taught by telling. The highest three are process-oriented, with no "right" answer - best taught through problem solving.

Each subject and grade level should have at least one activity that goes into the higher order thinking skills area. Most curricula are based upon breadth (material to be covered) and neglect the experience of studying, practicing, revising and refining a skill until a high order of competence is achieved. Usually, this is only experienced in extra-curricular activities such as sports, music, plays, etc., but shouldn't all students experience this part of the learning curve?

What are we going to do about including the future in schools?

We have neglected the integration of the three time frames for too long. History courses should emphasize the processes, attitudes and skills of historical research, as if this were the student's last history course and what they learned would have to serve them for the next 60-80 years. These research techniques would be used in all other subject areas to develop the student's historical perspective within a discipline's context (math, science, physical education, technology, etc.).

A course in future studies would emphasize the concepts, attitudes and projection techniques that can be used in other subject areas so as to enable students to better design and handle the future. One of the essential steps in the "futuring" process is to understand how present characteristics have developed from past events or trends, in order to project this into the future. Teachers will have to provide a better balance between "what" to learn and "how" to learn. Should we teach people to fish as well as give them a fish?

What are we going to do about other items on the agenda?

- How can we increase the amount and improve the quality of in-service time so that we can focus on improvements? Too many teachers "live in a cave," and need some fresh air.

- How can we get some of the university research to apply to problems in K-12 schools? (University researchers generally live in a "tower.")

- How can we get community involvement in career education? It is not working the way it is now.

- How can we get a greater focus on transferable skills? Rapid change demands this concern in schools.

- Why do we still require teachers to "carry bedpans" rather than utilizing more para-professionals?

- Why don't more subjects use "the game" as a motivator as sports, music and dramatics do?

- Why do we allow skilled professionals (teachers) to be unemployed for three months a year in their profession?

- Do we ever offer students an option to materialism?

- Why don't we provide more leadership in environmental solutions?

- Why are cooperative work groups more prevalent outside of schools than inside?

Things to think about while driving to work: 
- How can educational leaders take the initiative from governmental officials for policy decisions?

- Is there any evidence to support the assertion that students interrupt their education when they attend school?

- What would happen if teachers were empowered with status, knowledge and access to decision making?

- How do we reduce the confrontation between the teacher who operates on an ad hoc basis and the administrator who is driven by policy?

- What happens to the joy of learning that is so evident in the early years of a child's life?

- Maybe Allison Davis (sociologist from University of Chicago) was correct when he said that schools teach the unimportant things so the informal educational system can teach the important aspects of living in a society.

- Francis Drake, 1578, when his fleet ran into some troubles part way around the world said, the rules of discipline which should govern any hazardous undertaking should be:

Equal sharing of hardship and labor

No privilege for rank

Entire subordination to the commander

Need to be a company, all together

"Let us not give occasion to the enemy to rejoice in our decay." 。 